\title{
AEDES AEGYPTI E AEDES ALBOPICTUS NO BRASIL
}

\section{Sr. Editor}

Durante a realizaçào do XXV Congresso da Sociedade Brasileira de Medicina Tropical, em Florianópolis, Santa Catarina, entre 26 de fevereiro e 2 de março deste ano, houve oportunidade de discutir-se, mesmo que ainda sem a profundidade necessária, a situação atual do Brasil e de quase a totalidade dos paises do Continente no que se refere à infestação pelo mosquito Aedes aegypti e aos riscos para a saúde humana desta infestação.

A presença reconhecida do Aedes aegypti em pelo menos 13 estados do Pais e do Aedes albopictus em pelo menơs 4 , mantém o risco de ocorrência de epidemias de dengue e de casos urbanos de febre amarela.

A Superintendència de Campanhas de Saúde Pública tem desenvolvido esforços no sentido de reduzir a infestação pelo Aedes aegypti, e proteger contra febre amarela as populações sob risco de adoecerem pela sua forma silvestre, por meio da vacinação sistemática dos moradores das áreas rurais da região endèmica do país (mais de 5 milhões de $\mathrm{Km}^{2}$, incluindo a Amazônia e a região Centro-Oeste).

A redução da infestação pelo $A$. aegypti pela SUCAM enfrenta dificuldades técnicas, operacionais e financeiras de elevadas magnitudes.
O combate ao $A$. albopictus, também registrado no pais desde 1986, é ainda mais dificil por sua maior valència ecológica.

Desta maneira torna-se, a meu ver, imperiosa a necessidade de em algum momento haver um aprofundamento da discussão das medidas que devem ser tomadas para prevenir ou controlar epidemias. Esta discussão deve ser realizada entre representantes da SUCAM, do Ministério da Saúde, das Secretarias Estaduais e Municipais de Saúde e representantes da comunidade cientifica, particularmente os vinculados à Sociedade Brasileira de Medicina Tropical, Sociedade Brasileira de Infectologia e outras entidades afins.

$O$ problema, pela sua gravidade, não pode ficar restrito à SUCAM, que sozinha não tem condiçōes de estabelecer todas as medidas necessárias à prevenção e controle de enventuais epidemias decorrentes da presença no território brasileiro dos principais vetores da febre amarela, do dengue e de algumas encefalites.

\section{Atenciosamente \\ Pedro Luiz Tauil}

Prof. do Depto. de Saúde Coletiva

Faculdade de Ciências de Saúde

Universidade de Brasilia 